\title{
Preservar o excesso: LOPES, Silvina Rodrigues. A anomalia poética. Belo Horizonte: Chão da Feira, 2019.
}

\author{
Mariana Pereira Guida \\ Universidade Federal de Minas Gerais (UFMG), Belo Horizonte, Minas Gerais / Brasil \\ marianapereiraguida@yahoo.com
}

https://orcid.org/0000-0002-1482-4719

No ensaísmo de Silvina Rodrigues Lopes é digno de nota o olhar reincidente sobre certa impropriedade da literatura (o desajuste, a estranheza, o atrito, a monstruosidade...), sempre no encalço de uma anomia arisca, que nela resiste ao tratamento teórico. Em a anomalia poética, conjunto de ensaios publicado pela Chão da Feira, o leitor é incitado a tatear algumas partes dessa criatura quando ela se aproxima do discurso crítico, observar os seus rastros quando ela não lhe é mais tangível e perscrutar os seus rumos a partir da memória da sua passagem. Silvina desenvolve uma reflexão que se estabelece marginalmente, vacilando, distanciando e aproximando as posições de onde se toma a literatura, o que estremece os tapumes das "Ciências Humanas" e faz ressoar algo no ponto cego de todas elas. Divididos em três capítulos (I. ficção e testemunho; II. o artifício, a técnica; III. valor), os ensaios perpassam questões relativas à história, à linguagem e ao sentido para dimensionar em que termos a literatura responde a cada qual sem se encerrar em nenhuma delas.

literatura e circunstância colocará em discussão o pressuposto da "exigência de sentido", apontando como esta "rasura o acontecimento" e, por conseguinte, deixa de lado o elemento decisivo da circunstância, cuja "força do contínuo linguagem-mundo" "leva os outros domínios do pensamento a questionarem a sua própria estabilidade" (p. 13). Silvina pontua que sua dupla ação sobre o imaginário - "ao mesmo tempo passividade radical e esforço de libertação do fascínio em que 
se dissolveria" - expõe a necessidade de distinção acurada entre a ficcionalidade e a literatura, na medida em que esta última sobrepõe sensível e inteligível sem dialetizá-los, dispondo da capacidade de se retirar dos âmbitos institucionais que tendem a aprisioná-la e garantindo sua sobrevivência pelo saber de uma "memória não-subjectiva" (p. 28). Essa anterioridade diria, portanto, de uma intimidade construída sob uma aceitação pactuada no ato da leitura e extensiva à atividade crítica, na qual a singularidade seria garantidora da potência gerada pela multiplicidade de respostas à obra.

literatura no limite da ficção detém-se sobre a relação entre literatura e ficção suscitada no ensaio anterior e aqui explorada a partir da defesa da limiaridade da literatura como elemento de distinção em relação a uma ficcionalidade geral. Retomando a interpolação de uma "tradição fundacionalista" subordinada a um "telos definido como lei de unidade da composição" (p. 41) pela razão kantiana e o espraiamento da "filosofia do 'como se' a outras esferas da atividade humana" (p. 45), compreende-se a emergência de uma pletora de teorias de apelo igualmente teleológico a respeito da relação do objeto artístico com o ficcional. A passagem do dois ao três encontraria seus termos na formulação do sublime kantiano, conjugando "um esforço de representação que assim se concretiza na fragmentação e na quebra de ligações e não tanto, ou não apenas, no confronto com a ideia de irrepresentável" (p. 60).

Em da necessidade à intranquilidade, por sua vez, Silvina estabelece como ponto de partida a vinculação por vezes denegada entre o humano e o terror, para desenvolver uma reflexão sobre a intimidade da literatura com a morte. Se o terror permeia a história humana que se constitui sob "a consciência de mortalidade e o desejo de encontro" ( $p$. 62) importaria relacionar o seu "desaparecimento do horizonte político do Ocidente" (p. 62) à sedimentação de processos de violência sob a condição de estatuto tácito. Numa chave batailliana, o âmbito das criações culturais não completamente submetidas à institucionalização da cultura ainda reside a possibilidade de veiculação do terror enquanto "experiência de mortalidade" (p. 66) frente à "matriz asfixiante" e ao imperativo da identidade da economia capitalista.

estilo, gênese e exemplaridade propõe-nos acompanhar uma breve arqueologia do conceito de estilo e suas imbricações nos processos de institucionalização da arte que visam a sua assimilação pela cultura. Curiosamente, é a partir da implosão do estilo pelas vanguardas do século 
XX e do "estilhaçamento dos aparelhos institucionais de conformação e circunscrição da arte" (p. 83), que Silvina identifica a emergência da percepção do estilo sob o princípio de exemplaridade, "o facto de exercer um efeito, simultaneamente de reconhecimento e incitação" (p. 86). A exemplaridade, portanto, conduziria o estilo a uma condição de hibridez constitutiva, sendo ele "menos um conjunto de traços identificadores, mas, pelo contrário, (...) seu movimento de fuga à identificação" (p. 88).

Já em literatura e hipertexto, Silvina apresenta uma contrariedade de início: a das definições de hipertexto nos campos da informática e da literatura. Seu argumento é o de que as possibilidades de ruptura da sequencialidade suscitadas pela eletrônica "de facto não rompem com ela, pelo contrário, apenas impõem uma soma de sequências" (p. 90). Se o hipertexto eletrônico apenas reproduz a operação combinatória e replicadora da escrita, a literatura, por seu turno, conta com o "momento decisivo da leitura": enquanto "tensão para escapar ao infinito" (p. 94) estabelece a "relação de extensão e intensidade" (p. 95). Por isso, a noção de hipertextualidade acrescenta aos estudos literários quando lhes remete a essa condição contingente e histórica, ou seja, quando permite a realização plena da leitura literária, "impossível como automatismo" (p. 104). uma paisagem estranha desenvolve a crítica à homogeneização da lógica eletrônica contrapondo à "simetria especular" reprodutora "da oposição entre o homem e técnica" (p. 111) ao elogio da estranheza. Tudo leva a crer, entretanto, que fundamental ao ensaio é a paisagem estranha que o compõe, um suplemento, um "anexo" que narra uma cena paródica do esboroamento da "equação arte $=$ verdade suprema $=$ poder" (p. 115), protagonizada pelo Professor Pasmolive, uma espécie de "duplo verbal perfeito" de Dr. Pangloss, que tem a sua monomania do "PROJECTO" abalada por um "desvio" - uma "algazarra de fantasmas: crianças, cães que correm" (p. 121) e devorada pela "brecha" que se abre no meio da terra, a violência própria do devir de vida e morte que o Professor recusava.

Em impróprio para consumo parte-se da premissa pela qual na obra de arte "a relação do finito ao infinito" (p. 128) mantém-se pelo compromisso constantemente renovado entre o gesto do artista e seu público para analisar os problemas que se desdobram dos esquemas de gestão política que a ela se aplicam. Da irresolução do 'cálculo' do poeta no mundo à recusa da subordinação às instituições pela arte do século XX culmina-se em "admiti-la como elemento da vida" (p. 135), o que 
implica em "um mundo da arte isolado da vida", "um campo autônomo (...) e assente no pressuposto de uma clivagem entre a vida identificada com a ordem biológica (...) e uma transcendência constitutiva da ordem do sentido" (p. 139). Por isso, em nome da aceitação do diálogo como garantidor da arte, Silvina propõe a admissão da recusa ao imperativo da popularização e à "tirania do marketing" (p. 141).

No ensaio a arte, afirmação incomensurável, dedicado à memória de Daniel Costa, uma análise da relação entre teoria e prática nos processos de produção e circulação da arte a partir da obra de Daniel conduz o leitor para a reflexão sobre a decisão que sustenta a relação do teórico com as obras. Frente à "dualidade endeusamento-aproveitamento" da arte contemporânea, "cabe ao pensamento abrir as portas para o exterior dessa oposição” (p. 153). A partir daí percebe-se que não é a teoria produzida num vácuo especulativo, tampouco experimentação que visa a um efeito planejado, mas sim de um encontro que se dirige ao inacabado que o pensamento surge como "desejar e guardar no coração aquilo que nos aproxima e faz pensar” (p. 157). nascer da memória também trata da memória na (da) obra de Daniel Costa, uma reflexão de certo modo conduzida pelo olhar do artista que percebia seu trabalho " "no limite" " da adesão e da ruptura com as imposições do mundo da arte. Há da parte de Silvina uma confiança no entrançamento da promessa que alimenta a expectativa e o excesso que garante o inacabamento da arte, dela desdobra-se também um pensamento "no limite" que encontra na obra de Daniel o potencial vertical do "voo que nasce da memória": " a possibilidade de flutuar num espaço sem clivagens" em que "o fundo sustenta a forma porque é da mesma natureza que ela” (p. 163).

a anomalia poética apresenta as linhas gerais do contexto pelo qual a arte contemporânea é sustentada, grosso modo, por premissas que minam a irredutibilidade que lhe é fundamental. Do "marketing econômico" ao "marketing simbólico" (p. 165), verifica-se um niilismo que pressupõe a previsibilidade de "criadores" e "consumidores" de arte (p. 168), algo que Silvina contestará pela retomada do conceito de poiesis e sua íntima vinculação a uma práxis, um trabalho que se dá, sobretudo, na leitura. Na leitura enquanto "duelo com o indizível que só cada um pode travar" (p. 171) residem, portanto, a desmedida e o desafio da anomalia poética. arte, política, a volta ao mar colocará em questão a tendência autocrática dos discursos que advogam pela autonomia do sentido, aspecto que pelo menos desde Nietzsche tende a conduzir o 
teor constatativo da denúncia à "ressonância inquietante" (p. 174) de um "ressentimento justificado" (p. 175). Na medida em que opera sob a lógica opositiva, a demanda por valores é refratária à mudança intrínseca ao gesto criador, de modo que pensar em uma racionalidade estética cujo critério principal de avaliação seja a exigência de coerência" em maior ou menor medida implica no reconhecimento de uma "genealogia dos valores" da qual o conceito de cânone é exemplo. Logo, à leitura do texto literário só restaria o que restou aos navegantes portugueses do século XVI lançados ao mar sob a vertigem dos ventos contrários: "entregar-se ao turbilhão dos ventos para daquilo que parecia um obstáculo fazer um aliado, arriscando corajosamente a construção de uma hipótese" (p. 187).

Ao fim do percurso, o leitor poderia supor ter em mãos a reposta para a questão suscitada no início deste texto, sobre a reincidente escolha de Silvina pela dissonância, pelo desvio, pela quebra, pela diferença. Mas se a literatura é aquele estremecimento que vem das interferências dos discursos que colocamos em obra a partir das obras, não há ensinamento ou resposta possível além da inquietação do pensamento a que elas no lançam pela leitura. A partilha da leitura mostra, mais do que demonstra, o segredo sem mistério da anomalia poética, que nos é revelado de saída no livro: "a cada obra corresponde uma potência de percepção/ expressão (...) que só pode ser um gesto sem autoridade, fragmentário, de criação do múltiplo irredutível" (p. 7).

Data de recebimento: 4/12/2020

Data de aprovação: 9/12/2020 